\title{
METAMORFOSEIO-ME PARA AGRADAR AO PRÓXIMO: TELECO, O COELHINHO DE MURILO RUBIÃO
}

\section{ME METAMORFOSEIO PARA AGRADAR EL PRÓXIMO: TELECO, O COELHINHO DE MURILO RUBIÃOO}

\author{
Andre Rezende Benatti ${ }^{1}$
}

\begin{abstract}
Resumo: Buscando compreender um pouco acerca da realidade humana, esta análise do conto "Teleco, o coelhinho", (1965), no livro Os dragões e outros contos, de Murilo Rubião, pretende analisar os aspectos que mesclam, na narrativa, realidade e fantasia na construção dos valores humanos. Tomando por base os acontecimentos que giram em torno do personagem Teleco e que são narrados em primeira pessoa por um narrador personagem, nossa pesquisa perpassa para a inquirição da realidade fantástica à construção da personagem do coelho. Para tal, tomamos como base maior "Introdução à Literatura Fantástica", de Tzvetan Todorov (1992), para além de referências teóricas acerca dos estudos literários e culturais.
\end{abstract}

Palavras-chave: “Teleco, o coelhinho”; Literatura Fantástica; Murilo Rubião.

Resumen: En la búsqueda de comprender un poco de la realidad humana, este análisis del cuento "Teleco, o coelhinho"(1965), en el libro Os dragões e outros contos, de Murilo Rubião, pretende analizar los aspectos que mezclan en la narrativa, la realidad y la fantasía en la construcción de los valores humanos. Basado en los acontecimientos que giran en torno al personaje de Teleco y que son narrados en primera persona por un narrador/personaje, nuestra investigación se vale de la exploración de la realidad fantástica a la construcción del personaje del conejo. Para ello, tomamos como mayor base "Introducción a la literatura fantástica", de Tzvetan Todorov (1992), aparte de referencias teóricas acerca de los estudios literarios y culturales.

Palavras clave: "Teleco, o coelhinho"; Literatura Fantástica; Murilo Rubião.

\section{INTRODUÇÃO A UMA FANTASIA AGRADÁVEL}

No que concerne o vasto leque de produções artísticas contemporâneas, conceitos e escritos e todo tipo de produção artística sobre o fantástico vem se proliferando em ficções cada vez mais sombrias nas quais fantasia e realidade se mesclam a ponto do leito/espectador não conseguir diferenciar completamente se o que ocorre na diegese se passa com a personagem em ações reais a seu mundo ou se são frutos de sua mente, quem não se lembra da célebre película $O$ labirinto do fauno, dirigida em 2006 por

\footnotetext{
${ }^{1}$ Doutorando em Letras Neolatinas: estudos literários hispânicos, pela Universidade Federal do Rio de Janeiro - UFRJ. Professor de Literatura Espanhola, na Universidade Estadual de Mato Grosso do Sul UEMS/Campo Grande.
} 
Guilhermo del Toro. O fantástico caracteriza-se no texto literário, pelo extraordinário, ou seja, que foge da normalidade sem, necessariamente, estar fora ou dentro do "real". Literatura Fantástica segundo Todorov (1992) é aquela que nos causa hesitação, ou um estranhamento diante dos acontecimentos ou mesmo diante de uma personagem.

Neste trabalho, que toma como teórica Introdução a Literatura Fantástica, de Tzvetan Todorov (1992), faremos um breve estudo sobre o conto Teleco, o coelhinho, de Murilo Rubião. Destacaremos no decorrer do enredo o processo de metamorfose sofrida pelo personagem principal e pelos acontecimentos incomuns acontecidos durante a narrativa. Utilizaremos também neste trabalho outras referências teóricas relativas às teorias da narrativa, como Aspectos do Romance, de Edgar Morgan Forster, do qual tomaremos pequenas notas que não influem na "mudança", por assim dizer, da forma do que é tratado no estudo de Forster, o romance, da forma a qual analisaremos neste texto, o conto.

Quando iniciamos qualquer discurso sobre o conto, existe sempre certo desentendimento entre escritores, críticos e teóricos quando se pretende definir o que realmente é um conto, mesmo que aprendamos sempre que determinados textos se chamam contos por apresentarem uma ou outra caractarística, Julio Cortázar, em Valise do Cronópio, se refere a "esse gênero de tão difícil definição, tão esquivo nos seus múltiplos e antagônicos aspectos" (CORTÁZAR, 1974, p.147). No mesmo ensaio, Cortázar, comenta:

Se não tivermos uma idéia viva do que é um conto, teremos perdido tempo, porque um conto, em última análise, se move nesse plano do homem onde a vida e a expressão escrita dessa vida travam uma batalha fraternal, se me for permitido o termo; e o resultado dessa própria batalha é o conto, uma síntese viva e ao mesmo tempo uma vida sintetizada. (CORTÁZAR, 1974, p.147)

A origem do conto é muito remota, pois esse se inicia por meio da tradição oral até que chegue às manifestações escritas, como não se lembrar dos Contos das mil e uma noites. Entretanto, segundo Massaud Moisés (1973, p.97), é a partir da Idade Média que o conto começa a ser cada vez mais difundido, graças à prosificação das gestas cavalheirescas, até chegar ao que conhecemos hoje por conto. $O$ ato de contar, de comunicar sempre esteve na essência humana, naturalmente o homem necessita contar 
suas experiências, sua vida, sua visão de mundo, o narrar é uma necessidade humana por isso contar algo a alguém sempre esteve presente na história do ser humano.

Assim definindo, o narrador figura entre os mestres e os sábios. Ele sabe dar conselhos: não para alguns casos, como o proverbio, mas para muitos casos, como o sábio. Pois pode recorrer ao acervo de toda uma vida (uma vida que não inclui apenas a própria experiência, mas em grande parte a experiência alheia. O narrador assimila à sua substância mais íntima aquilo que sabe por ouvir dizer). Seu dom é poder contar sua vida; sua dignidade é contá-la inteira [...] (BENJAMIN, 1987, p. 221)

O conto é uma narrativa breve que se passa, não raro, em único lugar, abrangendo um espaço de tempo curto e com número reduzido de personagens. Por ser uma narrativa curta, geralmente, rejeita as divagações e as extrapolações da linguagem, portanto é objetivo, vai direto ao assunto sem se deter em pormenores, ficando à cargo do seu leitor as imagens, sugestões, ações das entrelinhas textuais.

O conto é do prisma de sua história e de sua essência, a matriz da novela e do romance, mas não significa que deve poder, necessariamente, transformar-se neles. Como a novela e o romance, é irreversível: jamais deixa de ser conto à narrativa que como tal se engendra, e a ele não podem ser reduzidos nenhum romance ou novela. (MOISÉS, 1973, p.99)

De acordo com Hermann Lima (1952, p.32), o conto pode ser distinguido por modalidades e dentro delas ser subdivididos como tradicionais literárias e fantásticas. Os contos tradicionais têm muitos traços em comum, são narrativas breves, com números reduzidos de personagens, uma só ação, espaço e tempo reduzido. O conto Fantástico é uma das formas mais livres de escrever, pois permite à imaginação, um vasto desenvolvimento. Não é somente uma criação de diferentes tipos de pessoas e criaturas, inclui também drama e aventura, que se distinguem em muitos aspectos do conto tradicional.

Segundo Todorov,

O fantástico puro implica, portanto não apenas a existência de um acontecimento estranho, que provoca hesitação no leitor e no herói; mas também numa maneira de ler, que se pode por ora definir negativamente: não deve ser nem "poética", nem "alegórica". (TODOROV, 1992, p.38) 
A narrativa fantástica se define como um acontecimento natural/não natural, que não poderia ser explicado pelas leis conhecidas desse mundo empírico, uma ilusão de sentidos, um produto da imaginação. Em uma segunda hipótese, esse acontecimento seria parte de uma realidade, mas regido por leis que desconhecemos e com os quais raramente tenhamos nos deparado. O fantástico seria, portanto, essa hesitação experimentada pelo ser que só conhece as leis naturais e se depara com um acontecimento sobrenatural.

Nos contos de Murilo Rubião notamos essas características, personagens irreais imersas num cotidiano vivido pelo leitor ou, ao contrário, personagens que encarnam homens normais imersas em situações improváveis. Ainda que as personagens ou seu mundo estejam a dizer que o que se lê não é "real" tal como o imaginamos ou podemos imaginar dentro de uma lógica, então somos levados a entrar num mundo a cada linha mais natural. E esse aspecto torna surpreendentes os contos de Rubião, logo, pretendemos analisar e refletir sobre os aspectos e as configurações fantásticas, presentes no conto "Teleco, o coelhinho".

Impelido com a ligeireza a unidade dramática que constrói a narrativa de "Teleco, o coelhinho", de Murilo Rubião, que tem como célula básica o artifício da metamorfose do coelhinho Teleco em múltiplos outros bichos, a história, pela rapidez e parcimônia de recursos é um conto, que recorre ao fantástico como recurso de estabelecimento da verossimilhança.

\footnotetext{
Num mundo que é exatamente o nosso, aquele que conhecemos, sem diabos, sílfides nem vampiros, produz-se um acontecimento que não pode ser explicado pelas leis deste mesmo mundo familiar. Aquele que o percebe deve optar por uma das duas soluções possíveis; ou se trata de uma ilusão dos sentidos, de um produto da imaginação e nesse caso as leis do mundo continuam a ser o que são; ou então o acontecimento realmente ocorreu, é parte integrante da realidade, mas nesse caso esta realidade é regida por leis desconhecidas para nós. (TODOROV, 1992, p.30)
}

O conto "Teleco, o coelhinho", publicado na coletânea Os dragões e outros contos, em 1965, pelo escritor mineiro Murilo Rubião, representa com astúcia o aspecto irreal da essência do homem, a probabilidade de transformação do homem em diferentes outras 
formas, a metamorfose. A narração conta a história de um coelho que pode se metamorfosear em diversos animais.

\title{
1. UM NARRADOR FANTÁSTICO
}

Se narrar é o ato de contar um fato, um episódio,

\begin{abstract}
Havemos de concordar que o aspecto fundamental do romance é contar uma estória, mas manifestamos nosso assentimento com matizes distintos, e é precisamente do nosso tom de voz que dependerão nossas conclusões subsequentes. [...] Um romance conta uma estória. É este o aspecto fundamental sem o qual ele não existiria. $O$ fator mais elevado que todos os romances têm em comum. (FORSTER, 2004, p.47-48)
\end{abstract}

Temos de concordar com Forster (2004), em tal afirmação, no entanto, nos vemos obrigados de ampliar tal protesto, pois, o ato de narrar não é exclusivo do Romance, enquanto gênero, o ato de contar está entranhado em todas as ações de memória humana. $\mathrm{Na}$ afirmação de Forster (2004), a nós, nos interessa somente, a partir da concepção que temos que o romance é uma narrativa, e, portanto, conta uma história. Assim, logo podemos afirmar que toda narrativa conta uma história, e se o Conto é uma narrativa, este conta uma história. E é exatamente a história, ou melhor, o modo como foi contada a história do conto "Teleco, o coelhinho", de Murilo Rubião, em que se mesclam realidade e fantasia, que nos interessa explorar neste trabalho.

O narrador, um colecionador de selos, conhece Teleco na praia e leva-o para sua casa. A partir daí, tornam-se grandes amigos. Teleco, para agradar a todos, transforma-se nos mais diversos bichos. Agradava-lhe ser gentil com as crianças e velhos, divertindo-os ou dando-Ihes ajuda. Certo dia, Teleco traz para casa uma bela mulher, chamada Teresa. Então Teleco passa a se afirmar homem, e por nome toma Antônio Barbosa. $O$ narrador/amigo de Teleco, então, apaixona-se por Teresa e a pede em casamento. Teresa recusa, dizendo que Teleco vale muito mais que ele. Passado alguns dias, o narrador conta que, ao chegar a casa, encontra Teresa e, Teleco, agora Antonio Barbosa dançando indecentemente, de rostos colados. Indignado, o narrador/amigo, os expulsa de casa. Uma noite, quando o narrador está distraído colando selos em seu álbum, vem por janela adentro um cachorro. Era Teleco. Perguntado por Teresa, Teleco dá respostas 
confusas, transformando-se incontrolavelmente em vários animais. Ele está doente, com uma tosse nervosa e nem ao menos consegue se alimentar, pois ora sua boca é grande demais para o alimento, ora é pequena demais, por conta de sua constante metamorforização. Cansado, por vigiar Teleco vários dias, o narrador/amigo adormece. Quando acorda, percebe que Teleco esta morto e transformado em uma criança suja.

O conto "Teleco, o coelhinho" é apresentado ao leitor com um trabalho de linguagem fácil em relação ao uso de palavras "estranhas" e/ou pouco conhecidas, o que faz com o leitor se prenda ao conto do inicio ao fim de maneira fácil, permitindo assim um grande mergulho na história narrada sem dificuldades. Por meio de tal trabalho de linguagem, Murilo Rubião cria um narrador/personagem que se espanta com o "estranho", mas que narra de forma a contar tal estranho de maneira comum, o estranho, fantástico, não pode ser, nem há maneira para que ele seja ignorado pelo leitor no conto, pois a estranheza, já vem impressa no próprio narrador.

Segundo o próprio Rubião (apud, SCHWARTZ, 1982, p.4), "Reelaboro a minha linguagem até a exaustão, numa busca desesperada da clareza, para tornar o conto o mais real possível", o que pode ser visto em "Teleco, o coelhinho", a qualquer nível de leitura, por meio do narrador.

O narrador/personagem é uma presença marcante na obra, ele narra os fatos e ao mesmo tempo esta ali participando de toda aquela ação dando novas expectativas à narrativa. Ele narra em primeira pessoa. Trata-se de um "eu" dentro da narrativa, que vive e registra os acontecimentos sob uma ótica individual e como personagem secundária que pode observar, do interior, os acontecimentos, e, portanto, dá-los ao leitor de modo mais direto, mais verossímil,

Como personagem secundária, ele narra da periferia dos acontecimentos, não consegue saber o que se passa na cabeça dos outros, apenas pode inferir, lançar hipóteses, servindo-se também de informações, de coisas que viu ou ouviu, e, até mesmo, de cartas ou outros documentos secretos que tenham ido cair em suas mãos. Quanto à distância em que o leitor é colocado, pode ser próxima ou remota, ou ambas, porque esse narrador tanto sintetiza a narrativa, quanto a apresenta em cenas. Neste caso, sempre como ele as vê. (LEITE, 1994, p. 37 - 38) 
O narrador do conto vive lado a lado com a personagem principal, Teleco, presenciando todas suas ações, mas nunca sabendo o que se passa na mente do próprio coelhinho.

[...] Contava-me acontecimentos extraordinários, aventuras tamanhas que o supus com mais idade do que realmente aparentava.

Ao fim da tarde, indaguei onde ele morava. Disse não ter morada certa. A rua era o seu pouso habitual. Foi nesse momento que reparei nos seus olhos. Olhos mansos e tristes. Deles me apiedei e convidei-o para residir comigo [...] (RUBIÃO, 1999, p. 144)

Todas as informações que nos são transmitidas, tudo o que sabemos sobre Teleco são impressões ou opiniões do narrador sobre ele, ou ainda, o que "aprendeu" por conviver com o coelho.

Todorov (1992) ressalta a importância deste narrador no conto fantástico:

[...] o narrador representado convém ao fantástico, pois facilita a necessária identificação do leitor com as personagens. O discurso deste narrador possui um estatuto ambíguo e os autores o têm explorado diferentemente enfatizando um ao outro de seus aspectos: quando concerne ao narrador, o discurso se acha aquém da prova da verdade; quando à personagem, deve se submeter à prova. (TODOROV, 1992, p.94)

No conto, podemos observar essas impressões deixadas pelo narrador e 0 personagem. Ambos vivem em constante harmonia desde o primeiro contato, sem causar espanto algum ao narrador. Após conhecer realmente seu hóspede, acontecem suas primeiras metamorfoses onde o narrador e o personagem começam a entrar em conflito, mas é importante ressaltar aqui que em nenhum momento narrador e o canguru interrompem sua amizade pelo motivo de se metamorfosear.

É interessante notar essa participação do narrador nesse conto, pois ele narra e participa de toda a ação do conto e isso acaba instigando e até mesmo prendendo o leitor no desencadear da narrativa.

\section{SOBRE AS METAMORFOSES DE TELECO, O COELHINHO}


Por metamorfose compreende-se, na maioria dos dicionários, mudança de forma física ou moral, transformação. No mundo em que Teleco vive a metamorfose funciona como um "mecanismo de defesa", contra a hostilidade que se faz presente no mundo urbano moderno.

\section{Chamava-se Teleco.}

Depois de uma convivência maior, descobri que a mania de metamorfosear-se em outros bichos era nele simples desejo de agradar ao próximo. Gostava de ser gentil com crianças e velhos, divertindo-os com hábeis malabarismos ou prestando-lhes ajuda. O mesmo cavalo que, pela manhã, galopava com a gurizada, à tardinha, em lento caminhar, conduzia ancião ou inválido às suas casas. (RUBIÃO, 1999, p. 144-145)

Assim, como um "combate" a este mesmo mundo, ou melhor, às pessoas que vivem neste mundo.

Não simpatizava com alguns vizinhos entre eles o agiota e suas irmãs, aos quais costumava aparecer sob a pele de leão ou tigre. Assustava-os mais para nos divertir que por maldade. As vítimas assim não entendiam e se queixavam à polícia, que perdia tempo ouvindo as denúncias. Jamais encontraram em nossa residência, vasculhada de cima a baixo, outro animal além do coelhinho. (RUBIÃO, 1999, p.145)

$\mathrm{Na}$ narrativa curta essas transformações acontecem desde $\mathrm{O}$ inicio até $\mathrm{O}$ fim. A narração, como dito, conta a história de um coelho que se metamorfoseia em diversos animais para o agrado de todos, Teleco é único, isolado em suas metamorfoses, usandoas para aproximar-se de todos, buscando um lugar, um reconhecimento, uma identidade.

Como uma metáfora do homem, Teleco é muito mais que um simples animal; observamos no conto que suas transformações mostram a inquietação do ser que quer sempre mais, sempre busca se adequar ao que the é taxado pelo meio em que vive. $A$ narrativa nos faz questionar a identidade do próprio ser humano, este ser múltiplo, este verdadeiro camaleão, que se adapta a todo o momento para sobreviver.

Para Schopenhauer (1991), o isolamento é um estado no qual o homem tem o privilegio de conhecer a si próprio: 
É na solidão que se conhece a mediocridade ou a grandeza de espírito, logo é só na solidão que cada um pode se conhecer a si mesmo. A que conclusão esta nos leva? A de que, quanto maior for à capacidade espiritual e interior do indivíduo, mais solitário ele será. Mas é um benefício para ele já que a solidão física se adéqua a sua qualidade espiritual. Ao contrário se ele estiver num contesto tumultuado, conflitante com seu próprio ser, estaria sendo roubado do convívio com seu eu e que não lhe traria qualquer beneficio ou compensação (SCHOPENHAUER, 1991, p.91)

Logo, podemos pensar que o ser humano usa do isolamento para, de certo modo, conseguir compreender a si próprio e o que está à sua volta, refletindo, até mesmo sobre sua condição enquanto homem, em um meio, social, no qual todos devem ser "normais". $\mathrm{Na}$ narrativa de Murilo Rubião em que Teleco representa essa realidade, de um ser oprimido, que vive de acordo com o que os outros querem, apenas para agradar a quem está à sua volta,transformando-se em vários bichos.

A ação da personagem de se metamorfosear funciona como intento de agradar e se defender ao mesmo tempo, em determinadas passagens assume formas que "desarmam" a ação "agressiva" contra ele, fazendo, assim, com que ele seja "aceito" pelos demais.

- Vá embora, moleque, senão chamo a polícia.

- Está bem, moço. Não se zangue. E, por favor, saia da minha frente, que também gosto de ver o mar.

Exasperou-me a insolência de quem assim me tratava e virei-me, disposto a escorraçá-lo com um pontapé. Fui desarmado, entretanto. Diante de mim estava um coelhinho cinzento, a me interpretar delicadamente: (RUBIÃO, 1999, p.143).

Assim, o coelho se adéqua ao que lhe parece melhor, ao que mais lhe é aceito, e o que melhor causar uma boa impressão, um coelho delicado e bem educado? Murilo Rubião coloca em dúvida a personalidade do personagem, a identidade do sujeito fica à graça do que quer o outro, do que agrada ao outro Teleco nunca demonstra o que é realmente, ele jamais se permite ver. De acordo com Hall (2005): 
O sujeito assume diferentes identidades em diferentes momentos, identidades que não são unificadas ao redor de um eu coerente. Dentro de nos há identidades contraditórias, empurrando em diferentes direções, de tal modo que nossas identificações estão sendo continuamente deslocadas. Se sentirmos que temos uma identidade unificada desde o nascimento ate a morte é apenas porque construímos uma cômoda estória sobre nos mesmos ou uma catástrofe "narrativa do eu". A identidade plenamente identificada, completa, segura e coerente é uma fantasia. Ao invés disso à medida que os sistemas de significação e representação cultural se multiplicam, somos confrontados por multiplicidade desconcertante de identidades possíveis, com cada uma das quais poderíamos nos identificar ao menos temporariamente (HALL, 2005, p.10).

O coelho Teleco é o exemplo desta identidade momentânea, temporária, que nos afirma Hall (2005), pois ele vive e se transforma de acordo com o ambiente e com as pessoas que o cercam, mudando simplesmente para agradar, representando assim, este ser humano mencionado pelo estudioso.

O narrador presencia toda a trajetória do coelho em querer ser um humano, contando e participando dos fatos, como, por exemplo, quando o coelho encontra uma mulher por quem se apaixona, e, para viver esse romance, se transformar em "homem", Teleco toma a forma de um canguru com o comportamento de um humano. Diante disso, a relação entre o protagonista e o canguru se torna tensa, pois os dois estão apaixonados por Tereza, o que acaba levando à expulsão do coelho da casa do amigo:

Uma tarde, voltando do trabalho, minha atenção foi alterada pelo som ensurdecedor da eletrola, ligada com todo o volume. Logo ao abrir a porta, senti o sangue afluir-me à cabeça: Tereza e Barbosa, os rostos colados, dançavam um samba indecente. (...) Joguei Barbosa ao chão e the esmurrei a boca. Em seguida enxotei-os (RUBIÃO, 1999, p.150).

Teleco desaparece da vida do narrador, até que uma noite volta para a casa de seu amigo, doente clamando por ajuda. Agora, agradar às pessoas já não se faz mais pertinente, pois Teleco não mais consegue identificar-se, as metamorfoses tornam-se constantes, descontroladas. Não tarda para que Teleco consiga a sua última e tão esperada metamorfose, a dele mesmo, ser humano, uma criança, suja, encardida, morta.

O processo da metamorfose no conto se faz como uma busca pela identidade que é impulsionada pelo desejo de agradar os outros, mas acima de tudo de reconhecer-se em algum destes. Teleco procura na metamorfose uma maneira de aproximação entre o 
ser humano que ele é, mesmo que um ser marginalizado por si mesmo que não se reconhece como diferente, um ser que ninguém reconhece como humano e que está disposto a buscar sua aceitação a todo custo.

Em suas primeiras metamorfoses Teleco sempre se transformava em animais dóceis e meigos, com a preocupação de agradar ao próximo e por isso eram admiradas pelo narrador amigo. Não se contentando em somente ajudar ao próximo, Teleco queria ir mais além do que era, um simples e meigo animal, e buscando em si a forma humana ,Teleco se metamorfoseou num canguru.

Barbosa tinha hábitos horríveis. Amiúde cuspia no chão e raramente tomava banho, não obstante a extrema vaidade que o impelia de ficar horas e horas diante do espelho. Utilizava-se do meu aparelho de barbear, da minha escova de dente e pouco serviu comprar-lhe esses objetos. [...] Também a sua figura tosca me repugnava. [...] A pele era gordurosa, os membros curtos, a alma dissimulada. (RUBIÃO, 1999, p. 148)

Teleco, agora Barbosa ao transformar-se em um canguru, tentava sua aproximação com o ser humano, mas não conseguiu. O narrador ainda o considerava como um animal repugnante. Apesar de suas múltiplas metamorfoses Teleco considerava ser um homem somente pelas atitudes tomadas por ele, portanto o narrador não 0 aceitava.

O coelho para de metamorfosear-se em outros animais e busca a forma física que o faz aproximar do homem. Essa busca pela identidade humana que ocorre com Teleco/Barbosa faz com que sua relação com o narrador entre em conflito. Apesar de ser um canguru, ele se vê e se comporta como homem, e isso acaba isolando-o a este mundo que tanto busca. No entanto, essas atitudes tomadas pela personagem na tentativa de aproximação com o humano e até mesmo por usar tais objetos do narrador, nos mostram que isso não era o suficiente para ser humano, pois era necessária uma construção de sua própria identidade. Outra característica que marca essa busca pela identidade de Barbosa é Tereza por quem se apaixonou, e de forma metafórica ela tem um caso com ele. Certo dia ao chegar do trabalho, o amigo de Barbosa se depara com os dois em sua sala, indignado com aquela cena expulsa Tereza e Barbosa, violentamente, de sua casa. 
Após ser expulso de casa, Teleco retoma a sua vida de antes, sozinho e abandonado por Tereza em forma de um cachorro, volta à casa de seu amigo afirmando ser Teleco. Não conseguindo mais se controlar, Teleco se metamorfoseia por diversas vezes e, em estado doentio sua última metamorfose foi uma criança encardida, sem dentes.

Embora tenha assumido uma forma humana no fim de sua vida, a busca pela sua identidade acaba ali, em um sujeito totalmente destruído e degradado pela sociedade opressora. O conto nos leva a fazer uma reflexão da vida humana, e de como o homem está inserido dentro dessa sociedade opressora e, de certa forma, destruidora.

\section{CONCLUSÃO DE UMA FANTASIA HUMANA}

Em se tratando de análise e interpretação de uma obra literária, que é o objetivo de boa parte das pesquisas dos estudos de literatura, a questão de seus limites tem-se mostrado por demasiado dificultosa, bem como na teoria literária. "Não se pode fazer uma obra significar qualquer coisa: ela resiste e você tem de se esforçar para convencer os outros da pertinência de sua leitura." (CULLER, 1999, p. 68). Confirmando a ideia de Culler, acreditamos que pertinência é a palavra-chave para os estudos literários, não importando se a análise/interpretação é mitigada ou extremada. E é essa pertinência, essa atribuição pertinente de valor que buscamos ao ler, neste texto o conto de Murilo Rubião, uma leitura que não soe como uma discrepância entre obra e teoria.

O estudo realizado sobre o gênero em questão, fantástico, e a análise do conto de Murilo Rubião, nos permitiu a constatação de que tal conto utiliza o sobrenatural não apenas como forma de o leitor questionar a veracidade dos fatos presentes na narrativa, característica do fantástico, mas, sobretudo, como uma forma de chamar-lhes a atenção para a vida do homem contemporâneo. Logo, a função do fantástico, na narrativa, é a de conduzir o leitor a um questionamento da realidade, chamar sua atenção para algumas situações reais vivenciadas pelo ser humano, tais como a da própria identidade.

No conto Teleco, o coelhinho o autor expõe suas ideias se referindo à sociedade moderna, espelhando-se nos acontecimentos absurdos, e que sempre leva a degradação do indivíduo como um ser humano. Nessa perspectiva, o presente trabalho junto com a narrativa fantástica, não propõe uma solução ao problema aqui discutido, mas sim 
suscitar uma reflexão sobre o absurdo do mundo moderno em si e os aspectos que levam o homem a essa desumanização.

\section{REFERÊNCIAS BIBLIOGRÁFICAS}

BENJAMIN, Walter. Mágia e Técnica, arte e política: ensaios sobre literatura e história e cultura. $3^{a}$.ed. São Paulo: Editora brasiliense, 1987.

CORTÁZAR, Julio. Alguns aspectos do conto. In: Valise de cronópio. Tradução de Davi Arrigucci Júnior. São Paulo: Perspectiva, 1974.

CULLER, Jonathan. Teoria Literária: uma introdução. Trad. Sandra Vasconcelos, São Paulo: Beca Publicações Culturais, 1999.

FERREIRA, Aurélio Buarque de Holanda. Minidicionário da língua portuguesa.Rio de Janeiro.Nova Fronteira,2001.

GOULART, Audemaro Taranto. O conto fantástico de Murilo Rubião. Belo Horizonte, MG: 1995.

FORSTER, Edward Morgan. Aspectos do romance. Trad. Sergio Alcides. 4. ed. revisada. São Paulo: Globo, 2004.

HALL, Stuart. A identidade cultural da pós-modernidade. 10. ed. Rio de Janeiro: DP\&A editora, 2005.

LEITE, Lígia Chiappini Moraes. O foco narrativo. São Paulo: Ática, 1994.

LIMA, Herman. Variações sobre o conto. Rio de Janeiro: MEC, 1952.

MOISÉS, Massaud. A criação literária: introdução à problemática da literatura. 5 ed. revista e aumentada. São Paulo: Melhoramentos, 1973.

RUBIÃO, Murilo. Teleco, o coelhinho. In. : Contos Reunidos. São Paulo: Editora Ática, 1999.

SCHOPENHAUER, Arthur. Aforismos sobre filosofia de vida. Tradução de Gilda Martins Saldanha da Gama. Rio de Janeiro: Ediouro, 1991.

SCHWARTZ, Jorge. Murilo Rubião - Literatura Comentada. São Paulo: Abril Educação, 1982. 
Revista InterteXto / ISSN: 1981-0601

v. 7 , n. 2 (2014)

TODOROV, Tzvetan. Introdução à Literatura Fantástica. 2. ed., Trad. Maria Clara Correia Castello. São Paulo: Perspectiva, 1992. 